\title{
How to Buy Pest Control Services ${ }^{1}$
}

\section{Phil Koehler and Roberto Pereira ${ }^{2}$}

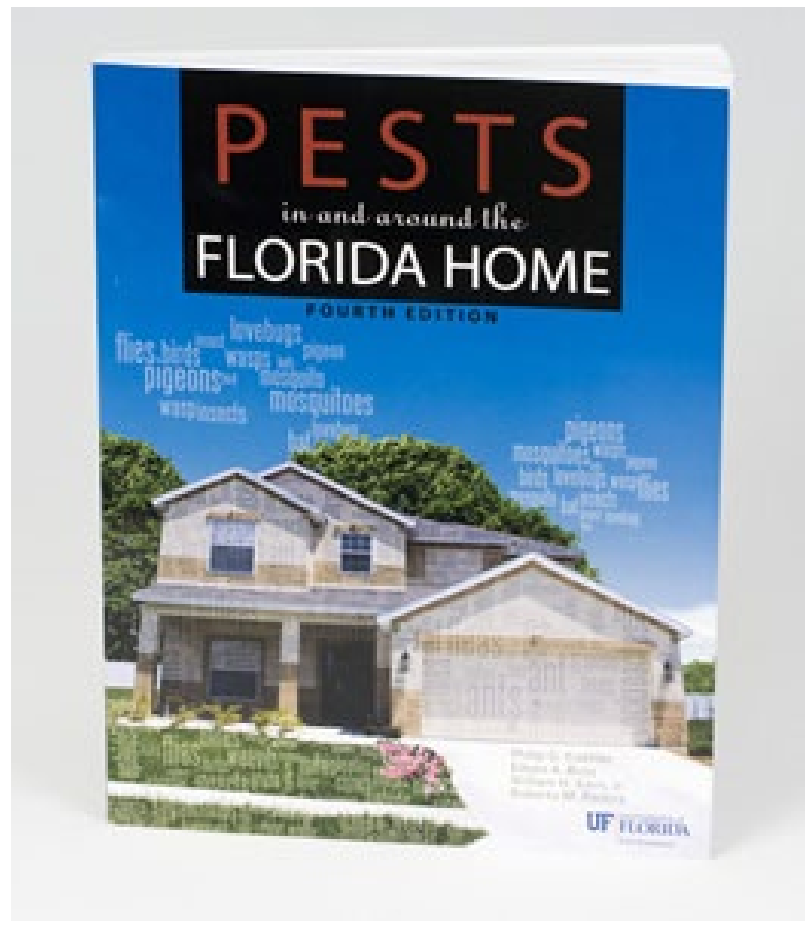

This fact sheet is excerpted from SP134: Pests in and around the Florida Home, which is available from the IFAS Extension Bookstore. http://ifasbooks.ifas.ufl.edu/p-154-pestsin-and-around-the-florida-home.aspx

Pest control, like any kind of business, is a joint venture between the company and the customer. As with many businesses, customers may have difficulty judging whether they have received the most skilled efforts for their money. This publication should help customers objectively look at the service they are buying to determine its merit.

\section{Organization of Pest Control Companies}

Pest control companies (Table 1) are operated by people who usually have been assigned to specific responsibilities within a firm. The general categories for personnel in a pest control firm are: business license holder, manager, certified operator, salesmen, and service technicians. Small firms may have one person performing all these functions.

The business license holder is the person who is licensed by the Florida Department of Agriculture and Consumer Services (FDACS), Bureau of Entomology, to operate a pest control business. The business license holder is responsible for records, reports, advertising, and personal protective measures. All records of pest control activities, including contracts, must be kept at the business location or at a specified location registered with FDACS. The license holder also takes responsibility for the accuracy of advertising and for protecting employees with necessary equipment for safe pesticide application. Licenses for pest control companies are only available from FDACS. Without the Department's license it is illegal for pest control services to be performed as a business.

The certified operator is in charge of the pest control activities of the business license holder. The certified operator is the professional in the company who has demonstrated competence in pest control and is responsible for supervision of all pest control work. Certified operators must pass a rigid examination to demonstrate competence. In order to qualify to take the examination, they must have a minimum

1. This document is ENY-219, one of a series of the Entomology and Nematology Department, UF/IFAS Extension. Original publication date August 1994. Revised July 2011 and July 2013. Visit the EDIS website at http://edis.ifas.ufl.edu.

2. Phil Koehler, professor, Entomology and Nematology Department; and Roberto Pereira, UF/IFAS Extension, Gainesville, FL 32611. 
of three years of documented employment in pest control or a college degree with advanced training or a major in entomology, ornamental horticulture, or pest control technology. Certified operators may become certified in four categories: general household pest control including rodent control, termites or other wood-destroying organisms, lawn and ornamental pest control, and fumigation. Companies with operators certified in all four categories may offer total pest control services; otherwise they may offer only services in the certification category of their operator.

In the company, the certified operator is responsible for the training and supervision of personnel in the use of methods and equipment which are known to provide the best pest control. The certified operator selects the pesticides and assigns only properly trained and qualified personnel to perform pest control work. All safety practices such as safe storage, application, and disposal of pesticides are his/ her responsibility. The quality of the service technicians in the company are a reflection of the quality of the certified operator.

The salesperson is hired to inspect premises, determine the extent of the problem, and give estimates for pest control work to be performed; the salesperson is sent to "sell" the company and its services to the customer. This is often a free service and customers should shop around to be certain the diagnosis of the problem is correct and the estimate is reasonable.

The service technician is the individual who does the actual pest control work. The quality of the control of pests depends to a large degree on the training the technician has received and the professionalism of the technician on the job. All pest control employees must carry a company identification card and must show it to you upon request.

\section{How to Select Pest Control Services Wisely}

Your first contact with a pest control company may be through a salesperson. A salesperson is sent to sell you pest control services. Salespeople are ambitious and some have been known to tell customers that a specific service is necessary when none is required. Selling unnecessary pest control services is prohibited by the pest control laws. Table 2 provides information about contracts and agreements you make with pest control companies. However, homeowners must buy pest control services wisely.

The following steps should be taken by homeowners to buy wisely:
Table 1. General facts about Florida pest control companies.

1. All pest control company employees who solicit, inspect or perform pest control work must carry a current identification card issued by the Florida Department of Agriculture and Consumer Services. The card has the employee's photograph, signature, name of employer, and expiration date. You have the right to ask to see it. Do not deal with a person who does not have valid identification.

2. All service vehicles are required to have the company name on each side in plain view. Do not deal with any pest control company or individual who arrives in an unmarked vehicle.

3. Infestation means the presence of LIVE pests. Ask the company representative to show you the live bugs or proof that they are still active. A reputable, honest inspector will make every effort to differentiate between old and on-going activity and will recommend corrective treatments only when necessary to stop an infestation.

4. Consumers should obtain inspections and cost estimates from at least two or more licensed companies, and compare their written proposals and contract terms. Comparison of the sketches or diagrams (which should indicate the location of infestations), contract terms, and cost estimates should be a good guide in determining whom to hire. Have the companies answer the following questions: what pests did they find, where did they find them, how do they propose to get rid of them, and what will it cost.

1.Shop around for the best service at a reasonable price.

2. If you do not know how to recognize insect infestation or damage, ask the salesman to show it to you. He or she must have evidence to recommend treatment.

3. Have the salesperson certify in writing that the premise or structure is infested with a specific pest and that a treatment is required.

4. You may confirm the salesperson's diagnosis by sending evidence of the pest or damage he shows you to the Cooperative Extension Service office in your county. An unbiased opinion may insure the proper treatment.

5. Get opinions from two or more pest control firms before deciding on expensive and extensive treatments.

6. Read the proposed contracts carefully so you know exactly what the company will do and guarantee. Ask the salesperson to interpret parts that you do not understand.

7. Check with the Better Business Bureau or web-based services (e.g., Angie's list) to ensure the company has a good record.

By following these procedures you are more likely to buy the services you need and want. 
Table 2. Facts about contracts/agreements with pest control companies

1. On June 7, 1974 the Federal Trade Commission's three day cooling off period for home solicitation sales became effective. Briefly, any sale with a value of $\$ 25$ or more in which the seller solicits you at your home must have language in their contracts informing you of these rights and furnish you with a "Notice of Cancellation." Chapter 501 of the Florida Statutes, the "Consumer Protection Act" is nearly identical to the FTC Act and any complaints may be directed to your local State Attorney's Office.

2. Florida regulations require that a copy of the proposed contract or other written agreement must be furnished to the property owner or his or her agent BEFORE performing any work and BEFORE receiving any payment. This written proposal must include certain specified information concerning the proposed job, such as the name of the pest requiring treatment, maximum cost of treatment (not including repairs) and warranty/ guarantee terms of the contracts. BE SURE YOU OBTAIN AND EXAMINE A COPY OF THIS INFORMATION BEFORE YOU ENTER INTO ANY WRITTEN AGREEMENT.

3. Don't be pressured into immediate treatment or signing a contract. Wood-destroying organisms such as termites, beetles, and wood-decaying fungi do not destroy property overnight or within a few days; it takes time. Don't make hasty decisions or sign a contract, work order, or proposal without taking the time to READ IT CAREFULLY to make sure it is suitable to your needs.

4. Termite and other wood-destroying organisms treatment contracts may provide for chemically RETREATING or REFUMIGATING your property in the event termites reappear, or may provide for REPAIR or REPLACEMENT of damaged wood caused by these organisms. READ YOUR CONTRACT CAREFULLY BEFORE SIGNING. If you don't understand it ask to have it explained to you. Your local Cooperative Extension office, a Consumer Affairs/Services Office or Florida Department of Agriculture and Consumer Services office would be glad to answer any questions.

5. Should a pest control company fail to perform according to the terms of its written contract or agreement, you may wish to request compliance assistance or file a complaint with your regional office of the Florida Department of Agriculture and Consumer Services, Bureau of Entomology and Pest Control. For compliance assistance requests, an inspector will look at your situation and explain whether a pest control company has fulfilled its contract obligations. If you file a complaint, an inspector will investigate your situation and report the results of the investigation back to you. Complaints are categorized as either a) failure to deliver services required by the contract/agreement, b) pesticide misuse, c) improper wood-destroying organisms report, or d) other miscellaneous types of complaints (e.g., unmarked/improperly marked vehicles, improper identification cards, unsafe practices). The pest control company is normally contacted during the course of these investigations. Florida regulations require that a pest control company must comply with all terms of its written contracts or agreements.

\section{Contracts for Wood-Destroying Organisms Control}

A pest control company must give you a written contract for each wood-destroying organism control or preventive treatment. The contract should be furnished before the work has begun and before any payment is made and contain the following information:

1. Name and address of property owner and address of property to be treated.

2. All buildings or structures to be included for treatment.

3. The complete name and address of the pest control firm.

4. Date of agreement, duration of contract, and renewal option (if offered).

5. Name of wood-destroying organisms covered by the contract.

6. Whether treatment is recommended for control of existing infestation or prevention of infestation.

7. Conditions under which the company will retreat in case of re-infestation.

8. Conditions under which repairs will be made.

9. Maximum price to be charged for treatment.

10. Whether re-inspections are to be made and, if so, how often, and how much they will cost.

11. What renewal fees will cost.

12. Maximum price for structural repairs, if any, shown separately.

13. If guaranteed with a bond, what the obligations of the bond are; for instance, retreatments, repairs, etc.

Wood-destroying organisms do not destroy property overnight. Take your time to read the contract and compare services. 


\section{What to Look for in the Delivery of Service}

All company employees who come to your house reveal the professionalism of the firm. Look for the following:

1. Is the vehicle in which they arrived dirty and messy? Is the vehicle plainly marked with the name of the company with whom you are dealing?

2. While performing the job, are they considerate, courteous, and careful with your belongings?

3. Do they replace items they move to do the job?

4. Are they organized or must they continually run to the truck for supplies?

If you are impressed with all the factors about the technicians, you have reason to believe they may be conscientious in their performance of pest control. However, all these are superficial and not alone a true indication of the effectiveness of the services they have rendered.

There are several direct indications of the quality of pest control services the company is delivering. Companies that are concerned about your safety will follow several basic rules. These are:

1. Pesticides should never be diluted in your house. Pesticides should always be diluted in or at the service vehicle or at the company's business location. Any applicator who dilutes pesticide in your home is not using approved pest control practices.

2. The technician should always leave his/her service equipment and pesticides in a locked vehicle or service compartment when not using them.

3. Pesticides should be applied indoors with low pressure to prevent splashing and runoff. Any spills or puddles should be wiped up immediately by the technicians. Technicians should come into your home with rags, etc., to wipe up accidental spills.

4. Every time a spray is applied indoors, you should be told to keep pets and children away from surfaces until they are dry. The technician should also request that anyone suffering from allergies, heart ailments, or respiratory problems be kept out of the room during the application, or that application be delayed until such persons can be removed.

5. Pesticides should never be applied to food products, utensils, or to surfaces that food will contact.
6. Applicators should be prepared to protect caged pets by covering them and should shut off air pumps in fish tanks. If cages are removed from rooms, they should check them to make sure they are free of pests.

7. The technician should never apply water-based pesticides to electrical equipment.

8. The technician should warn you to keep children and pets off lawns until the chemical has dried.

9. Poison baits should be placed where children or pets cannot get to them.

10. The technician should point out any damage present before spraying, such as stains, burns, etc., so you will not think spraying caused the problem.

11. Technicians should never give or sell pesticides to customers. Never ask the technician to give you a pesticide.

12. Children's toys, mattresses, and bedding should never be sprayed with pesticides.

\section{Complaints about Pest Control Firms}

It is against the law for a pest control firm or its employees to perform pest control in a negligent manner. It is also against the law for any pest control firm or its employees to knowingly make false or fraudulent claims, misrepresent the effects of materials or methods, or fail to use methods or materials suitable for the pest control undertaken. Fraudulent or misleading advertising is also against the law.

Pest control firms cannot tell you that a pest is infesting your property or structure, or tell you that a specific treatment for pest control is required, unless supporting evidence of an infestation exists.

A pest control firm violating the law may have its license or certificate suspended or revoked if the claims are proven. If you need information about a pest control service that you purchased, or have a pest control complaint regarding any negligence, fraudulent claims, or improper use of materials and methods, contact the nearest regional EntomologistInspector with the Florida Department of Agriculture and Consumer Services. The inspectors and their contact information are located at http://www.flaes.org/aes-ent/ inspector.html.

Also you are encouraged to write or call the Bureau of Entomology and Pest Control, 3125 Conner Blvd., Suite N, Tallahassee, Fl 32399-1650, telephone (850) 617-7997). 